\title{
Didática e estilos de uso do virtual para a Educação a Distância
}

\author{
Pedagogy and styles for virtual \\ Distance Education
}

Didácticas y estilos del uso del virtual

para la Educación a Distancia

DANIELA MELARÉ VIEIRA BARROS (iD ${ }^{a}$

\section{Resumo}

Falar de educação a distância está além de discutir a sua importância e necessidade, mas também a sua qualidade e sustentabilidade, tendências essas contínuas nas agendas das organizações que discutem o tema e que indicam diretrizes para a educação mundial. Para tanto, entendemos por qualidade e sustentabilidade em EaD questões que envolvem a formação do docente, do tutor, a elaboração dos materiais, a orientação didático-pedagógica dos cenários, os ambientes virtuais de aprendizagem e o conceito didático utilizado. A evasão dos estudantes e os problemas de aprendizagem e autonomia relacionados com o campo da EaD passam pelas individualidades e competências, no ser e estar no online. Esse perfil relaciona-se com a forma de uso do virtual, e sua fluência na utilização constante dos espaços, interfaces e ferramentas que cada um desenvolve e apropria-se. Tendo essa assertiva como eixo de análise, o presente artigo vem destacar a importância dos estilos de uso do espaço virtual para as aprendizagens na Educação a Distância. Assim, o estudo realizado traz

\footnotetext{
a Universidade Aberta (UAb), Lisboa, Portugal. Doutora em Educação Escolar, e-mail: daniela.barros@gmail.com 
resultados de investigações já desenvolvidas, fundamentadas e validadas cientificamente, cujo objetivo foi caracterizar a forma de uso do virtual e a sua influência nas estratégias didático-pedagógicas nos cursos de educação a distância. A metodologia de investigação utilizada foi a qualitativa. Os resultados destacam características e elementos para entender como os estilos de uso do espaço virtual facilitam a elaboração de estratégias de aprendizagem para as práticas pedagógicas em educação a distância, sugerindo e orientando a forma de utilizar.

Palavras-chave: Estilos de uso do espaço virtual. Educação a distância. Ensino e aprendizagem no assíncrono.

\begin{abstract}
Talking about distance education goes beyond discussing its importance and need, but also its quality and sustainability, trends that are continuous on the agendas of organizations that discuss the topic and that indicate guidelines for world education. We understand by quality and sustainability in distance education issues that involve the training of the teacher, the tutor, the preparation of materials, the didactic-pedagogical orientation of the scenarios, the virtual learning environments and the didactic concept used. The evasion of students and the problems of learning and autonomy related to the field of distance education go through individualities and skills in online. This profile is related to the way of using the virtual, and its fluency in the constant use of spaces, interfaces and tools that each one develops and appropriates. This statement in the article highlights the importance of styles of using virtual space for learning in Distance Education. Thus, the study brings results of investigations already developed, substantiated and scientifically validated to characterize the form of use of the virtual and its influence on didactic-pedagogical strategies in distance education courses. The research methodology used was qualitative. The results were characteristics and elements to understand how the styles of use of virtual space facilitate the development of learning strategies for pedagogical practices in distance education, suggesting and guiding the way to use it.
\end{abstract}

Keywords: Styles of use of virtual space. Distance education. Teaching and learning in asynchronous.

\title{
Resumen
}

Hablar sobre la educación a distancia va más allá de discutir su importancia y necesidad, pero también su calidad y sostenibilidad, tendencias que son continuas en las agendas de las organizaciones que discuten el tema y que indican pautas 
para la educación mundial. Con este fin, entendemos por calidad y sostenibilidad en temas de educación a distancia que involucran la capacitación del maestro, el tutor, la preparación de materiales, la orientación didáctico-pedagógica de los escenarios, los entornos virtuales de aprendizaje y el concepto didáctico utilizado. La evasión de los estudiantes y los problemas de aprendizaje y autonomía relacionados con el campo de la educación a distancia, pasan por individualidades y habilidades, en estar en línea. Este perfil está relacionado con la forma de usar lo virtual y su fluidez en espacios, interfaces y herramientas que cada uno desarrolla y se apropia. Con esta afirmación como eje de análisis, este artículo destaca la importancia de los estilos de uso del espacio virtual para el aprendizaje en la Educación a Distancia. Así, el estudio realizado arroja resultados de investigaciones desarrolladas, fundamentadas y validadas científicamente, cuyo objetivo era caracterizar la forma de utilizar lo virtual y su influencia en las estrategias didáctico-pedagógicas en los cursos de educación a distancia. La metodología de investigación utilizada fue cualitativa. Los resultados destacan características y elementos para comprender cómo los estilos de uso del espacio virtual facilitan el desarrollo de estrategias de aprendizaje para prácticas pedagógicas en educación a distancia, con orientaciones en la forma de usarlo.

Palabras clave: Estilos de uso del espacio virtual. Educación a distancia. Enseñanza y aprendizaje en asíncrono.

\section{Introdução}

O impulso inicial para este texto foi a importância crescente da individualização e personalização das aprendizagens, para atender às diferenças e potencializar as capacidades no digital. Para além disso, também destacamos a discussão dos elementos da Educação a Distância enquanto qualidade dos processos pedagógicos existentes.

Nesse sentido, desenvolveu-se aqui uma análise a partir das experiências vivenciadas nas práticas pedagógicas, expressas em: orientações de dissertações de mestrado e teses doutorais; produção de livros e artigos na área dos estilos de uso do espaço virtual; cursos a distância, frutos de investigações cientificamente validadas e projetos que culminaram numa síntese de reflexões e análises teóricas celebradas a partir dos resultados de mais de dez anos de trabalho desenvolvido. 
A problemática delineada está expressa numa síntese de resultados oriundos das investigações dos estilos de uso do virtual no desenvolvimento e potencialização das estruturas didático-pedagógicas da educação a distância.

Esses resultados vão desde o planejamento do conteúdo até a organização, roteiro e interfaces utilizadas nos ambientes de aprendizagem online. Diversificar, individualizar, personalizar e incluir são os verbos de ação que orientam e justificam os resultados aqui em análise.

Este estudo é justificado pela necessidade na área da educação online de direcionamento de referenciais didático-pedagógicos que ajudem a construir práticas inovadoras de aprendizagem e que, simultaneamente, atendam às necessidades emergentes.

O trabalho desenvolvido, de foro qualitativo, foi realizado através da análise descritiva, suportada por referenciais bibliográficos, reflexão e discussão das produções sobre os estilos de uso do virtual ao longo de dez anos de estudos na área.

O presente documento traz inovações, na medida em que sistematiza a aplicação direta dos estilos de uso do virtual de forma pedagógica, com estratégias que se encaixam em todas as dimensões da educação a distância, proporcionando elementos para análise e posterior melhoria nos aspetos pedagógicos e, consequentemente, a construção de melhores práticas no processo de ensino e aprendizagem em EaD.

A importância deste artigo reside na consolidação de como utilizar a teoria dos estilos de uso do virtual no trabalho com Educação a Distância. A elaboração do texto decorre de fundamentos envolvendo fases de investigação de vários contextos, com métodos de recolha de dados e com os resultados efetivos do tema em questão.

\section{Contexto do tema}

Algumas das investigações realizadas destacam elementos de análise que passam pelo uso do termo "estilos" em disciplinas inseridas na formação de 
professores como explicação da importância do uso das TIC para a aprendizagem, justificando o potencial diferenciador das mesmas na elaboração de estratégias pedagógicas Barros (2009).

Ademais dessa perspectiva, temos a caraterização de algumas ferramentas da plataforma moodle na forma de trabalhar os estilos e, dessa forma, ampliar e diversificar o trabalho educativo (ALVES; BARROS; OKADA, 2009). Os textos mais específicos sobre o tema dos estilos e a educação a distância foram de Barros et al. (2010) e Barros (2008), que foram elaborados a partir do trabalho realizado em um dos eventos online (em língua portuguesa) de educação a distância, na participação de uma lista de discussão em formato assíncrono, onde trouxeram à tona questionamentos e análises que puderam apontar caminhos para investigações.

$\mathrm{Na}$ sequência das reflexões os estudos entre Portugal e Inglaterra destacam os estilos na educação aberta e online, já analisando e discutindo suas possibilidades neste entorno (BARROS; OKADA, 2010).

Aprimoram estas discussões com a dinamização das redes e os diversos formatos de colaboração como fatores centrais nas aprendizagens; nesta vertente os estudos realizados destacaram elementos sobre os estilos de aprendizagem colaborativos para o e-learning. Esses estudos segundo Barros (2011b) priorizaram a questão da colaboração e a relação das características intrínsecas do perfil de cada estilo na dinâmica dos trabalhos em grupo, cooperativos e/ou colaborativos.

Juntamente com a questão da colaboração, os ambientes de aprendizagem também se tornam espaços de construção a partir dos estilos, com metodologias e formatos de trabalho diferenciados (BARROS; SPILKER, 2013). As percepções sobre o virtual como paradigma diferenciador para a educação advêm das reflexões sobre as mudanças ocorridas nas percepções do tempo e espaço, processos de comunicação e sua influência na forma de aprender (BARROS, 2012a).

Com a evolução dos processos colaborativos para a aprendizagem surgem então, com as reflexões na comunidade internacional da área dos estilos, 
os estilos de coaprendizagem (BARROS; OKADA; KENSKI, 2012; BARROS et al., 2012).

Já com os recursos abertos e as interfaces gratuitas e online, a discussão sobre as suas potencialidades na forma de trabalhar os estilos foi mapeada em estudos que descrevem a abrangência das interfaces para utilizar os estilos e os seus benefícios no formato a ser apresentado ao estudante (BARROS; SIMÕES, 2014).

Aprimorando os estudos sobre as tendências atuais, considerando os documentos para a melhoria qualitativa da educação e a convergência com as tecnologias (UNESCO e Horiz̧on Report 2030), as investigações sobre os estilos de uso do virtual chegaram às relações da personalização do ensino dentro do universal design for learning, caracterizando, assim, a sua importância para uma educação adaptativa, inclusiva e personalizada (BARROS, 2016a).

Os documentos da UNESCO (2002) sempre destacaram a importância da educação aberta e a distância para o atendimento das individualidades nas formas de aprender e a inclusão das diferenças. O mais recente documento NMC Horizon Report, da The New Media Consortium, uma entidade focada em discutir novas tendências de mídia, comunicação e educação, é um relatório global em que os dados apresentados recentemente sobre o ensino superior apontam, entre as várias tendências, os ambientes de aprendizagem personalizados e as tecnologias para a aprendizagem adaptativa. Esses indicadores direcionam-nos a valorizar e a utilizar, em contextos formais ou não formais de aprendizagem, estratégias que contemplem e valorizem a personalização, a inclusão e a flexibilidade (OTA; ARAUJO JUNIOR; BARROS, 2017).

Atualmente, o tema pode ser entendido como um referencial para aprimorar as estratégias de aprendizagem na educação a distância, chegando a destacar as redes sociais na formação de professores como forma de aprendizagem para a construção da docência e do pensamento pedagógico da educação online. Portanto, apresenta-se como teoria que fundamenta as 
estratégias didático-pedagógicas para o trabalho docente (TERÇARIOL; BARROS, 2017a; TERÇARIOL; BARROS, 2017b.

Ao longo dos últimos anos, o tema da educação a distância sempre esteve presente nos estudos, investigações e discussões realizadas a partir dos estilos de uso do virtual. A metodologia de ensino em educação a distância sob a abordagem dos estilos de uso do espaço virtual facilita compreender a dimensão da docência de forma assíncrona (BARROS, 2017).

Neste documento estarão sistematizados aspetos teóricos relacionados com o referencial aqui apresentado, de forma a consolidar os estilos de usar o virtual como potencialidades da construção de estratégias pedagógicas para a aprendizagem assíncrona. Deixamos claro neste artigo que a teoria referencial utilizada, dos estilos da aprendizagem, é a da vertente Iberoamericana, utilizada nas investigações da área em língua espanhola e portuguesa (ALONSO; GALLEGO; HONEY, 2012), bem como a análise de algumas teorizações derivadas do mesmo referencial.

\section{Indicações metodológicas do estudo aqui apresentado}

Tendo por problemática apresentada a reflexão que envolve uma personalização mais concreta nas metodologias online e por objetivo analisar a importância dos estilos de uso do espaço virtual para as aprendizagens na Educação a Distância, a metodologia utilizada foi a qualitativa, a partir dos referenciais já mencionados.

O período do levantamento dos dados e informações foi de 2009 até 2019. Esse período foi selecionado como marco referência pelo ano de criação dos estilos de uso do virtual e sua utilização, consolidado ao longo dos dez anos, em várias investigações, em dois idiomas e em vários contextos e países.

O levantamento das informações foi realizado pelo arquivo pessoal da investigadora, com as produções da rede e da revista de estilos de aprendizagem, que se mantém ativa com interações e investigações em curso. 
Utilizaram-se também bases de dados na área da educação em língua portuguesa e espanhola, fruto de teses e dissertações que envolviam o tema.

Os resultados numéricos e estatísticos não serão aqui analisados pelo volume de informações e a necessidade do trabalho a ser realizado. Aqui somente apresentaremos as sínteses qualitativas das discussões e as propostas que subsidiam as práticas em desenvolvimento.

Também tomamos em consideração os resultados dessas práticas que estão em processo e que apresentam inovações no formato e na construção de estratégias para cursos a distância, totalmente assíncronos.

\section{Alguns dos resultados identificados sobre os estilos de uso do virtual em cenários de Educação a Distância}

Nos últimos anos, a teoria dos estilos de aprendizagem, base conceptual dos estilos de uso do virtual, tem sido alvo de análise e crítica relativamente à sua validade e importância. Normalmente, os argumentos passam pela não comprovação científica ou verificação da influência do tema sobre os aspetos pedagógicos. Riener e Willingham (2010), Newton (2015) e Kirschner (2017) destacam o que chamam de "mito" e tratam o tema nesta perspetiva. Em geral, abordam somente os autores anglo-saxões, desconsiderando completamente os estudos e abordagens latino-americanas e ibero-americanas, sendo que os argumentos estão voltados para a relação dos estilos com questões físicas ou de inteligência. Para além disso, existem muitas percepções e afirmações distorcidas sobre este tema.

Portanto, deixamos claro que os estilos de uso do virtual estão trabalhados na perspetiva das estratégias didático-pedagógicas ao longo de quase dez anos de estudos e investigações, evoluindo e verificando o trabalho concreto e atuante nos caminhos da aprendizagem.

Em cenários assíncronos, a forma de uso do virtual ajuda-nos a verificar a importância de diferentes estratégias, com diferentes interfaces online para o 
processo educativo, exatamente pela oferta de possibilidades que esses aplicativos oferecem para atender às preferências e individualidades.

A teoria clássica dos estilos e o seu desenvolvimento ao longo da sua história foi estruturada a partir de referenciais de presencialidade e não para cenários assíncronos, portanto, havia necessidade de surgir uma adaptação da mesma aos contextos online. Considerando esta informação juntamente com a necessidade de entender a forma como as pessoas utilizavam o virtual, motivouse a investigação e a construção dos estilos de uso do espaço virtual. Segundo Barros (2014), são eles:

- O estilo participativo, que considera a participação como elemento central, no qual o indivíduo deve ter a ambiência do uso do online;

- O estilo de busca e pesquisa, que tem como elemento central a necessidade de fazer pesquisa online, procurando informações de todos os tipos e formatos;

- O estilo de estruturação e planejamento, que tem como elemento central a necessidade de desenvolver atividades que valorizem os aplicativos para elaborar conteúdos e atividades de planificação;

- O estilo concreto e de produção no virtual, que tem como elemento central ações concretas de produção no online e a rapidez na realização desse processo.

Considerando essas assertivas, a teoria de estilos fornece algumas diretrizes para compreendermos melhor como aprender e como ensinar em cenários online. Para tanto, destacamos os elementos que suportam o uso da teoria de estilos na educação a distância (BARROS et al., 2010):

- Atendimento das individualidades dos estudantes;

- Ênfase no processo metodológico;

- Desenvolvimento de estratégias didático-pedagógicas com base nos estilos;

- Ampliação das possibilidades de avaliação do aluno; 
- Aprimoramento das formas de aprendizagem no processo educativo a distância.

$\mathrm{O}$ atendimento das individualidades refere-se a atender, de forma atenta e direcionada, às dificuldades de aprender de cada um. A proposta não está pensada para somente agrupar por estilos, mas sim trabalhar na diversidade e proporcionar aos estudantes estratégias que os ajudem nas estruturas pessoais de aprendizagem. A decisão de agrupar estudantes com estilos iguais ou diferentes estará também diretamente relacionada com a natureza do conteúdo a ser abordado e a abrangência da proposta das atividades. Tarefas mais específicas beneficiam estilos específicos e tarefas mais amplas requerem a combinação de vários estilos na mesma equipa. O ideal é combinar diferentes estilos de acordo com as propostas das estratégias, propiciando igualmente o desenvolvimento de novas competências, que vão tornando os estudantes mais capacitados nas diversas situações de aprendizagem (BARROS et al., 2010).

As ferramentas e interfaces online podem ser escolhidas seguindo os critérios dos estilos; todas elas contemplam os estilos dependendo das estratégias pedagógicas utilizadas. Na verdade, a escolha das ferramentas não pode ser o foco principal, mas sim o uso que vai ser feito delas.

Os estilos de uso do virtual ajudam-nos a verificar a importância do uso das tecnologias no processo educativo, exatamente pela oferta de possibilidades que as suas interfaces, ferramentas, recursos e aplicativos oferecem para atender às preferências e individualidades na aprendizagem.

A aplicação dos estilos de uso do espaço virtual em diversos contextos ocorre já há dez anos. Uma investigação recente das informações panorâmicas sobre o tema e sua aplicação realizou um levantamento de dados, estabelecendo uma base informativa que identificou sua aplicação em cinco países diferentes: Brasil, Espanha, México, Portugal e Chile. Para além disso, também identificou dissertações e teses que utilizaram o questionário e artigos que trabalharam com a sua aplicação em diversos contextos para diversos objetivos.

Os principais resultados comprovados estavam relacionados a: identificação da forma de uso do virtual para o desenvolvimento de estratégias 
pedagógicas em aulas presenciais, o uso do questionário para a estruturação de ambientes virtuais de aprendizagem, a identificação do perfil dos nativos, residentes, imigrantes e visitantes virtuais (SCHERER, 2005; WHITE; CORNU, 2011), o desenvolvimento de espaços em redes informais de aprendizagem e a organização de cursos online com as orientações dos estilos de uso do virtual na concepção das atividades e exercícios propostos.

As dificuldades encontradas passam exatamente pela construção das estratégias e a forma como organizá-las diversificando as opções. Os docentes em geral têm grande dificuldade em realizar uma convergência entre as ferramentas, aplicativos e softwares disponibilizados e a construção pedagógica de como ensinar no online. O processo de transposição didática que realizam da sua capacidade docente é deficitário e passa somente pelo que chamam de "criatividade" sem elementos e indicadores da área da didática que facilitem essa convergência (AMADOR et al., 2016).

Os resultados apontam para propostas de exercícios, atividades e tarefas sem um pensamento abrangente de opções e percursos. Estes acabam se definindo em um formato único, basicamente propostas que passam por discussões e reflexões em fóruns e realização de uma tarefa ou exercício ou atividade a respeito do tema, para cumprir, assim, os objetivos e desenvolver competências do conteúdo ali trabalhado. Para além desses formatos únicos, existe desconhecimento e grande ambiquidade na diferença entre interação, comunicação e direcionamento pedagógico dos estudantes nos ambientes de aprendizagem.

O referencial teórico desenvolveu-se nos últimos anos consolidando os resultados acima descritos em diferentes contextos, como podemos verificar em algumas das referências mais recentes — Barros (2019), Terçariol \& Barros (2017a; 2017b) Ota, Araujo Junior \& Barros (2017), Barros, Matos dos Santos \& Sánchez Romero (2019), Santo et al. (2019), Barros (2018) - e anteriores, como: Barros (2009), Miranda et al. (2016), Barros (2016b), Gallego, Alonso \& Barros (2015), Barros (2015), Barros (2014), Barros (2012a) e Barros (2011a). 
Estudos realizados sobre essa temática, juntamente com a teoria de estilos de aprendizagem, além de propiciarem a identificação de diferentes perfis na forma de aprender no virtual, ainda apontam caminhos para direcionar as estratégias didático-pedagógicas em qualquer ambiente de ensino. De facto, alguns estudos ainda empíricos têm indicado a importância dessa teoria para a educação a distância, no que diz respeito à melhoria qualitativa dos processos de ensinar e de aprender. A oferta de atividades e materiais didáticos diversificados direcionados às preferências de aprendizagem contribuem para essa melhoria.

Os aspetos metodológicos que envolvem a educação a distância devem levar em consideração as especificidades do contexto virtual. Os estilos de uso do espaço virtual para a educação a distância podem ser orientadores em todos os elementos que o constituem, a partir de três eixos: diversificação de ações, atividades, exercícios ou tarefas; diversificação de caminhos de aprendizagem; diversificação de ferramentas, interfaces e aplicativos.

Em linhas gerais, a Educação a Distância, no seu formato completamente assíncrono, apresenta as seguintes unidades de contexto da estrutura técnica e pedagógica para um curso online: aspetos pedagógicos e didáticos do curso, modelo metodológico utilizado; aspetos técnicos do curso, plataforma, design, ferramentas, recursos e aplicativos utilizados; aspetos de conteúdo do curso, quem realiza e como é disponibilizado; aspetos assíncronos de comunicação e interação entre estudantes e formadores/tutores - fóruns; aspetos de avaliação dos estudantes; aspetos sociais/relacionamento/ comportamento entre estudantes e docentes/tutores; aspetos de usabilidade do curso (BARROS; NEVES, 2017).

Destacamos a seguir as diretrizes orientadoras da teoria dos estilos de uso do virtual para cada uma das denominadas unidades de contexto da educação a distância: 
Quadro 01 - Educação a Distância e Estilos de uso do Virtual

\begin{tabular}{|c|c|}
\hline $\begin{array}{l}\text { Unidades de contexto da } \\
\text { estrutura técnica e pedagógica } \\
\text { para um curso à distância. }\end{array}$ & $\begin{array}{l}\text { Diretrizes orientadoras a partir dos } \\
\text { estilos de uso do virtual, características } \\
\text { de aplicação. }\end{array}$ \\
\hline $\begin{array}{l}\text { Aspetos pedagógicos e didáticos } \\
\text { do curso, modelo metodológico } \\
\text { utilizado }\end{array}$ & $\begin{array}{l}\text { Orientações de aprendizagem ao estudante, } \\
\text { modelo de metodologia de ensino, quais os } \\
\text { caminhos que o estudante poderá utilizar } \\
\text { para aprender determinado objetivo e } \\
\text { competência. }\end{array}$ \\
\hline 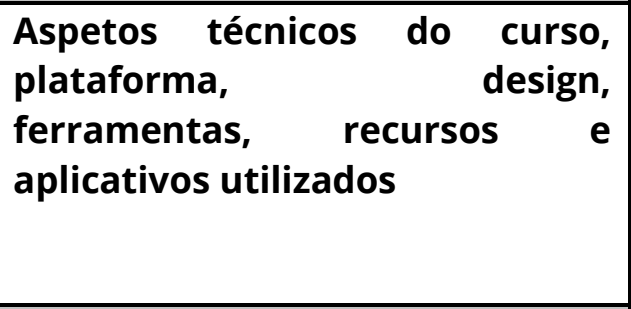 & $\begin{array}{l}\text { Selecionar ferramentas da web } 2.0 \\
\text { juntamente com as ferramentas da } \\
\text { plataforma, considerar para tanto os tipo de } \\
\text { ações que cada uma facilita ao estudante e } \\
\text { que sejam diversificadas para tender aos } \\
\text { diferentes estilos. }\end{array}$ \\
\hline $\begin{array}{l}\text { Aspetos de conteúdo do curso, } \\
\text { quem realiza e como é } \\
\text { disponibilizado }\end{array}$ & $\begin{array}{l}\text { Formato de como será disponibilizado para } \\
\text { o estudo, que não é somente realização de } \\
\text { atividade, exercício ou tarefa, mas sim como } \\
\text { deve ser estudado o conteúdo, auxiliando na } \\
\text { diversidade dos formatos de aprendizagem. }\end{array}$ \\
\hline $\begin{array}{lr}\text { Aspetos assíncronos } & \text { de } \\
\text { comunicação e interação entre } \\
\text { estudantes } & \text { e } \\
\text { formadores/tutores - fóruns } & \\
\end{array}$ & $\begin{array}{l}\text { Elaboração de processos de comunicação } \\
\text { com ações voltadas para a aprendizagem, } \\
\text { fóruns com atividades dentro de diversas } \\
\text { estratégias. }\end{array}$ \\
\hline $\begin{array}{l}\text { Aspetos de avaliação dos } \\
\text { estudantes }\end{array}$ & $\begin{array}{l}\text { As propostas de avaliação devem } \\
\text { contemplar uma diversidade de formatos, } \\
\text { preferencialmente na metodologia do } \\
\text { próprio curso e não uma atividade final e } \\
\text { única, não só um tipo de questão ou de } \\
\text { avaliação. }\end{array}$ \\
\hline $\begin{array}{l}\text { Aspetos sociais/relacionamento/ } \\
\text { comportamentor } \\
\text { estudantes e docentes/tutores }\end{array}$ & $\begin{array}{l}\text { Personalizar e dar feedback de forma ampla, } \\
\text { coletiva, incentivando e estabelecendo um } \\
\text { processo de comunicação contínuo e } \\
\text { assertivo. }\end{array}$ \\
\hline Aspetos de usabilidade do curso & $\begin{array}{l}\text { Disposição da tipologia de cenário e } \\
\text { ambiente a ser utilizado, simples, de fácil } \\
\text { acesso e operativo em qualquer sistema. o } \\
\text { diferencial dos cenários de aprendizagem é } \\
\text { a forma como se conduz o caminho de } \\
\text { aprendizagem e não a ferramenta em si. }\end{array}$ \\
\hline
\end{tabular}

Fonte: Elaborado pela autora. 


\section{Breves considerações sobre as diretrizes orientadoras dos estilos de uso do espaço virtual}

As implicações na área pedagógica são inúmeras, mas aqui analisadas considera-se a questão da centralidade do ensino no estudante. Este tipo de aprendizagem estrutura-se basicamente nas individualidades e nas opções pedagógicas, para atender às necessidades do aluno, em coerência com as necessidades do conteúdo a ser ensinado.

O estilo de ensinar também é uma implicação importante. Cada docente tem o seu estilo e, em geral, ensina como gostaria de aprender, tendenciando a sua forma de aprender sem considerar as demais. Essa é uma dificuldade presente, que exige do docente a capacidade de refletir sobre outras opções, tanto a nível de estratégias como de métodos de ensino.

De acordo com os estudos de Doyle \& Rutherfor (1984 apud ALONSO; GALLEGO; HONEY, 2002), quatro aspetos importantes devem ser considerados:

- O docente deve concretizar quais as dimensões da forma de aprender dos estudantes, considerando a idade, a maturidade e o tema que se está estudando;

- Deve diversificar os instrumentos e estratégias de acordo com as características dos seus estudantes;

- Verificar como organizar a diversidade de estilos com os métodos e estratégias de aprendizagem.

- É necessário verificar as possibilidades de desenvolver um trabalho desse nível, mas adequando as características do espaço virtual.

Os resultados das investigações apontam que o perfil de uso do virtual modificou-se ao longo dos anos de acordo com as opções e serviços que surgiram pelas ferramentas disponibilizadas, mas este é um tema que ainda 
deverá ser mais bem explorado e refletido e que aqui não temos espaço para o fazer.

A ação tutorial também deve considerar os estilos, em especial no atendimento individual do estudante e na melhoria na interação e processos de comunicação e inferência dos tutores no processo educativo a distância. As individualidades e os atendimentos personalizados são uma das grandes chaves para a boa qualidade dos cursos a distância (BARROS; NUNES, 2011; 2014; BARROS, 2012b; BARROS; REIS, 2009).

Os processos de avaliação deixam de ser um momento específico, mas passam a ser por fases e em convergência com as estratégias de aprendizagem. Isso acontece não só pela forma de elaboração das tarefas e/ou atividade e/ou exercício, mas sim pelas fases da realização dos mesmos, considerando os diferentes estilos. Estas fases representam um acúmulo ou nível de informações e conhecimentos para chegar ao objetivo e as competências estipuladas por determinado conteúdo.

A usabilidade pedagógica e técnica do curso também pode ser influenciada diretamente pelos estilos: no desenho do curso na plataforma, na construção dos espaços online específicos e nos cenários informais de aprendizagem.

A discussão da Educação a Distância, atualmente, em âmbito pedagógico, passa pela qualidade das ações e propostas, resignificando o paradigma das estratégias da docência para os caminhos de aprendizagem. A qualidade e sustentabilidade em EaD perduram na agenda das instituições internacionais responsáveis pelo tema e que fizeram da área da educação a distância um espaço continuo de discussão envolvendo as questões da própria formação docente, a tutoria, a elaboração dos materiais, a orientação didático-pedagógica dos cenários, os ambientes virtuais de aprendizagem e o conceito didático.

Pudemos portanto entender que os estilos de uso do virtual proporcionam elementos para a qualidade e sustentabilidade em EaD. Longe de finalizar as discussões sobre o tema, este breve artigo destacou, em linhas gerais, 
os caminhos onde o tema pode ser alargado, deixando pistas para aprofundar e ampliar as reflexões em questão.

\section{Referências}

ALONSO, C. M.; GALLEGO, D. J.; HONEY, P. Los estilos de aprendizaje: procedimientos de diagnóstico y mejora. 8. ed. Madrid: Mensajero, 2012.

ALVES, L.; BARROS, D. M. V.; OKADA, A. Moodle: estratégias pedagógicas e estudo de caso. Salvador: Eduneb, 2009. Disponível em: <http://livromoodle.blogspot.com/>. Acesso em: 20 dez. 2019.

AMADOR, F. et al. A transposição didática no ámbito do eLearning. In: DIAS, P.; MOREIRA, D.; QUINTAS-MENDES, A. Práticas e cenários de inovação em educação online. Lisboa: Universidade Aberta, 2016.

BARROS, D. M. V. Reflexões de base para a educação a distância: o virtual como novo espaço educativo. Revista UDESC Virtual, v. 1, p. 10-20, 2008.

BARROS, D. M. V. Guia didático sobre tecnologias da comunicação e informação para o trabalho educativo na formação docente. Rio de Janeiro: Vieira e Lent, 2009.

BARROS, D. M. V. et al. Estilos de aprendizagem e educação a distância: algumas perguntas e respostas?! Journal of Learning Styles, v. 5, n. 5, p. 1-10, 2010.

BARROS, D. M. V. Estilo de aprendizagem colaborativo para o e-learning. Revista Linhas, Florianópolis, v. 12, n. 2, p. 31-43, jul./dez. 2011a. Disponível em: <http://www.periodicos.udesc.br/index.php/linhas/article/view/2402>. Acesso em: 2 dez. 2019.

BARROS, D. M. V. (Org.). Estilos de Aprendizagem. Lisboa: [s.n.], 2011b. v. 1. Disponível em: < http://estilosdeaprendizagem-vol01.blogspot.com/>. Acesso em: 10 dez. 2019.

BARROS, D. M. V. Estilos de uso do espaço virtual: como se aprende e se ensina no virtual? Revista Inter-Ação, v. 34, n. 1, p. 51-74, 2012a. Disponível em: $<$ http://www.revistas.ufg.br/index.php/interacao/article/view/6542>. Acesso em: 5 jan. 2020 . 
BARROS, D. M. V. Estilos de aprendizaje y las tecnologías: medios didácticos en lo virtual. Madrid: Editorial Académica Española, 2012b.

BARROS, D. M. V. Estilos de aprendiragem e o uso das tecnologias. Santo Tirso: De Facto Editores, 2014.

BARROS, D. M. V. Estilos de aprendizagem e as tecnologias: guias didáticos para o ensino fundamental. In: TORRES, P. L. (Org.). Metodologias para a produção do conhecimento: da concepção à prática. Curitiba: SENAR, 2015.

BARROS, D. M. V. Educação a distância: universal design for learning, estilos de aprendizagem e personalização. In: SIED, ENPED - SIMPÓSIO INTERNACIONAL DE EDUCAÇÃO A DISTÂNCIA E ENCONTRO DE PESQUISADORES EM EDUCAÇÃO A DISTÂNCIA, 3., 2016, São Carlos. Anais... UFSCAR: São Carlos, 2016a.

BARROS, D. M. V. Estilos de Aprendizagem e Tecnologias. In: RAMAL, A.; SANTOS, E. (Org.). Mídias e tecnologias na educação presencial e a distância. Rio de Janeiro: LTC, 2016b. p. 233-241.

BARROS, D. M. V. Metodologia em EAD sob a abordagem dos estilos de uso do virtual. In: SIMPÓSIO DE EDUCAÇÃO, 6., ENCONTRO INTERNACIONAL DE POLÍTICAS PÚBLICAS, 3., 2017, Franca. Anais... Franca: UNESP; Uni-FACEF, 2017.

BARROS, D. M. V. Estilos de participação virtual; Estilos de Aprendizagem. In: MILL, D. (Org.). Dicionário crítico de educação e tecnologias e de educação a distância. Campinas: Papirus, 2018. p. 242-246.

BARROS, D. M. V. Padlet: estratégia didático-pedagógica em fóruns para cursos online. In: SANTOS, E.; PORTO, C. (Org.). App-Education: fundamentos, contextos e práticas educativas luso-brasileiras na cibercultura. Salvador: EDUFBA, 2019.

BARROS, D. M. V.; MATOS DOS SANTOS, V.; SÁNCHEZ ROMERO, C. Estratégias para o trabalho colaborativo: revisitando o uso de fóruns on-line na educação a distância. Revista Diálogo Educacional, Curitiba, v. 19, n. 60, p. 221-245, 2019. DOI: https://doi.org/10.7213/1981-416X.19.060.DS10

BARROS, D. M. V.; NEVES, C. Instrumento para identificação dos elementos pedagógicos do elearning no cenário empresarial. Revista Online de Política e Gestão Educacional, Araraquara, v. 21, n. 3, p. 1517-1549, set./dez. 2017. DOI https://doi.org/10.22633/rpge.v21.n3.2017.10971. 
BARROS, D. M. V; NUNES, J. S. Tecnologia Educativa, Presente e Perspectiva de Futuro no Brasil. Revista Educación y Futuro, Madrid, n. 25, 2011.

BARROS, D. M. V.; NUNES, J. Cursos DM\&JN: pesquisa e inovação para o teletrabalho docente. In: INTRACTEMBERG, L. (Org.). Docência online independente: novos horizontes profissionais na educação. Rio de Janeiro: Livre Docência, 2014.

BARROS, D. M. V.; OKADA, A. Estilos de aprendizagem na educação aberta online. In: SILVA, M.; PESCE, L.; ZUIN, A. Educação online: cenários, formação e questões didático-metodológicas. Rio de Janeiro: Editora WAK, 2010. p. 18-38.

BARROS, D.; OKADA, A.; KENSKI, V. Coletividade aberta de pesquisa: os estilos de coaprendizagem no cenário online. Educação, Formação \& Tecnologias, v. 5, n. 2, p. 11-24, 2012. Disponível em: <http://eft.educom.pt>. Acesso em: 20 dez. 2019.

BARROS, D. M. V.; REIS, V. A função tutorial na formação continuada docente. In: Revista iberoamericana de educación a distancia, v. 1, p. 10-20, 2009.

BARROS, D. M. V.; SIMÕES, P. Educação a distância e as novas estratégias pedagógicas: ferramentas da Web 2.0 e estilos de aprendizagem. In: MILL, D.; REALI; A. M. de M. R. Educação a distância e tecnologias digitais: reflexões sobre sujeitos, saberes, contextos e processos. São Carlos: Edufscar, 2014.

BARROS, D. M. V.; SPILKER, M. J. Ambientes de Aprendizagem Online: contributo pedagógico para as tendências de aprendizagem informal. Revista Contemporaneidade Educação $e$ Tecnologia, v. 1, n. 3, p. 28-39, abr. 2013. Disponível em: <http:// revistacontemporaneidadeeducacaoetecnologia03.files.wordpress.com/ 2013/05/artigo03_2013.pdf>. Acesso em: 20 dez. 2019.

BARROS, D. M. V. et al. Estilos de coaprendizagem para uma coletividade aberta de pesquisa. In: OKADA, A. (Org.). Recursos educacionais abertos e redes sociais: coaprendizagem e desenvolvimento profissional. Milton Keynes: KMi, 2012. Disponível em: <http://oer.kmi.open.ac.uk/?page_id=387>. Acesso em: 6 jan. 2020.

GALLEGO, D. J.; ALONSO, C. M.; BARROS, D. M. V. Estilos de aprendizaje: desafíos para una educación inclusiva e innovadora. Santo Tirso: Whitebooks, 2015. (Coleção Estudos Pedagógicos). 
KIRSCHER, P. A. Stop propagating the learning styles myth. Computers \& Education, v. 106, p. 166-171, mar. 2017. Disponível em: <https://www.sciencedirect.com/science/article/pii/S0360131516302482>. Acesso em: 5 jan. 2020.

MIRANDA, L. et al. Estilos de aprendiragem e inovação pedagógica. Santo Tirso: Whitebooks. 2016.

NEWTON, P. M. The learning styles myth is thriving in higher education. Frontiers in Psychology, v. 6, n. 1908, 2015. Disponível em: $<$ https://www.ncbi.nlm.nih.gov/pmc/articles/PMC4678182/>. Acesso em: 5 jan. 2020.

ORGANIZAÇÃO DAS NAÇÕES UNIDAS PARA A EDUCAÇÃO, A CIÊNCIA E A CULTURA (UNESCO). Open and distance learning: trends, policy and strategy considerations. 2002. Disponível em: $<$ http://unesdoc.unesco.org/images/0012/001284/128463e.pdf>. Acesso em: 18 jan. 2020.

OTA, M. A.; ARAUjO JUNIOR, C. F.; BARros, D. M. V. Estilos de aprendizagem em ambientes virtuais: cenários de investigação na educação superior. Educacãa Formação e Tecnologias, v. 10, n. 1 p. 47-58, jan./jul. 2017. Disponível em: <http://eft.educom.pt/index.php/eft>. Acesso em: 20 dez. 2019.

RIENER, C.; WILLINGHAM, D. The myth of learning styles. Change: the Magazine of Higher Learning, v. 42, n. 5, p. 32-35, 2010. Disponível em: <https://www.tandfonline.com/doi/abs/10.1080/00091383.2010.503139>. Acesso em: 6 jan. 2020.

SANTO, E. E. et al. Perfil de uso do espaço virtual como estratégia pedagógica para a práxis educativa. Online. EaD em Foco, v. 9, e781, 2019. DOI https://doi.org/10.18264/eadf.v9i781

SCHERER, S. Uma estética possivel para a educação bimodal: aprendizagem e comunicação em ambientes presenciais e virtuais. Tese (Doutorado em Educação) - Programa de Pós-Graduação em Educação, Pontifícia Universidade Católica de São Paulo, São Paulo, 2005.

TERÇARIOL, A. A. L.; BARROS, D. M. V. As Redes Sociais Aplicadas à Educação: Percepções de Professores em Formação Inicial. In: TORRES, P. (Org.). Redes e Mídias Sociais. 2. ed. Curitiba: Appris Editora, p. 19-40, 2017 a.

TERÇARIOL, A. A. L.; BARROS, D. M. V. Os estilos de uso dos espaços virtuais e as redes sociais na Pedagogia: um estudo exploratório. Journal of 
Learning Styles, v. 10, p. 321-356, 2017b. Disponível em: $<$ http://learningstyles.uvu.edu/index.php/jls/article/view/377>. Acesso em: 18 jan. 2020.

WHITE, D.; CORNU, A. Visitors and Residents: a new typology for online engagement. First Monday, v. 16, n. 9, 2011. Disponível em: $<$ http://journals.uic.edu/ojs/index.php/fm/article/view/3171/3049>. Acesso em: 20 dez. 2019.

RECEBIDO: 20/01/2020

APROVADO: 20/02/2020

RECEIVED: 01/02/2020

APPROVED: 02/20/2020

RECIBIDO: $20 / 01 / 2020$

APROBADO: 20/02/2020 